\title{
High- and low-temperature dual ferroelasticity in a new hybrid crystal: $\left(\mathrm{Me}_{3} \mathrm{NCH}_{2} \mathrm{CH}_{2} \mathrm{OH}\right)_{4}\left[\mathrm{Ni}(\mathrm{NCS})_{6}\right]$
}

\author{
De-Xuan Liu, Xiao-Xian Chen, Zi-Ming Ye, Wei-Xiong Zhang* and Xiao-Ming Chen
}

Ferroelasticity, as a mechanical counterpart of ferroelectricity and ferromagnetism, describes the nonlinear response of strain to stress with a hysteresis loop [1]. Ferroelastic phase features with two or more switchable orientation states of spontaneous strain $[2,3]$, ensuring essential roles in shape memory, actuators, and mechanical switches [4]. Traditional inorganic ferroelastics such as $\mathrm{Gd}_{2}\left(\mathrm{MoO}_{4}\right)_{3}$ [5], $\mathrm{Pb}_{3}\left(\mathrm{PO}_{4}\right)_{2}$ [6], $\mathrm{BiVO}_{4}$ [7,8] and $\mathrm{PbZr}_{1-x} \mathrm{Ti}_{x} \mathrm{O}_{3}$ [9] generally are faced with a technical problem in synthetic process that requires high temperature, high pressure, or high energy consumption. Recent years have witnessed the emergence of nontoxic, flexible, easily prepared, and highly designable molecule-based crystals as important alternatives for multi-functional materials [10-16]. However, the increased complexity arising from multi-atomic molecular components makes the underlying mechanism of ferroelasticity in such molecule-based crystals hard to be deeply and fully understood, thus it is challenge to design new types of molecular ferroelastics.

According to the 94 species of ferroelastic crystals suggested by Aizu [17], ferroelasticity emerges in a low-symmetry crystal system formed via a symmetry-breaking phase transition from a higher-symmetry crystal system (paraelastic phase). In general, decreasing temperature favors symmetry reduction, thus ferroelasticity generally only appears in the phases at the lower temperature. Such conventional symmetry-breaking phase transitions usually limit the application of ferroic materials at high temperatures. To promote the working temperature for ferroic materials, many efforts such as applying $\mathrm{H} / \mathrm{F}$ and $\mathrm{H} / \mathrm{OH}$ substitution on organic components have been made in recent years [18-24]. In this sense, an inverse symmetry-breaking phase transition, whose high-temperature phase (HTP) has a lower symmetry than low-temperature phase (LTP), provides a different approach to achieve a high working temperature, as demonstrated very early by the Rochelle salt, $\mathrm{KNaC}_{4} \mathrm{H}_{4} \mathrm{O}_{6} \cdot 4 \mathrm{H}_{2} \mathrm{O}$, undergoing an orthorhombic to monoclinic ferroelectric phase transition upon heating [25]. However, the documented examples of inverse symmetry-breaking phase transitions in molecular crystals are scarce [26-28], and the underlying mechanisms have rarely been studied.

In our ongoing studies on phase-transition hybrid crystals by assembling polar organic cations with inorganic components, we found that the hydroxyl-containing cations, taking capacity in forming coordination and hydrogen bonds, usually endow the hybrid crystals with complicated and nontrivial bond-switching transitions, accompanying with exceptional multiaxial ferroelectricity and ferroelasticity with large spontaneous stain
$[21,29]$. To increase the complexity for triggering nontrivial phase transitions, we employed a cholinium cation, $\mathrm{Me}_{3} \mathrm{NCH}_{2}$ $\mathrm{CH}_{2} \mathrm{OH}^{+}$, containing the ethylol group, to assemble with $\left[\mathrm{Ni}(\mathrm{NCS})_{6}\right]^{4-}$. We obtained a new $\mathrm{A}_{4} \mathrm{BX}_{6}$-type hybrid crystal adopting an anti- $\mathrm{XeF}_{4}$ structure (Scheme 1), $\left(\mathrm{Me}_{3} \mathrm{NCH}_{2} \mathrm{CH}_{2} \mathrm{OH}\right)_{4}\left[\mathrm{Ni}(\mathrm{NCS})_{6}\right]$ (1), which is, to the best of our knowledge, the first molecular crystal with low- and high-temperature dual ferroelasticity arising from a conventional and an inverse symmetry-breaking transition at 269 and $360 \mathrm{~K}$, respectively.

Compound 1 was synthesized by slow evaporation from aqueous dilute hydrochloric acid solutions of nickel nitrate, cholinium chloride, and potassium thiocyanate (detailed in the Supplementary information and Fig. S1). Thermal gravimetric analysis showed that 1 could be stable up to $490 \mathrm{~K}$ under $\mathrm{N}_{2}$ atmosphere (Fig. S2). Differential scanning calorimetry (DSC) showed that, during the heating/cooling recycles, two pairs of endothermic/exothermic peaks appeared at 269/264 K $\left(T_{\mathrm{cl}}\right)$ with a thermal hysteresis of $5 \mathrm{~K}$, and $360 / 357 \mathrm{~K}\left(T_{\mathrm{c} 2}\right)$ with a thermal hysteresis of $3 \mathrm{~K}$, respectively (Fig. 1a). For convenience, we label the phase below $T_{\mathrm{c} 1}$ as the LTP, above $T_{\mathrm{c} 2}$ as the HTP, and between $T_{\mathrm{c} 1}$ and $T_{\mathrm{c} 2}$ as the RTP (room-temperature phase).

Such two-step reversible phase transitions were further confirmed by temperature-dependent dielectric constant $\left(\varepsilon^{\prime}\right.$, Fig. 1b) and variable-temperature powder X-ray diffraction (PXRD) patterns (Fig. S3). Upon heating from $240 \mathrm{~K}$, the $\varepsilon^{\prime}$ value showed a rapid increase from ca. 4.09 at $270 \mathrm{~K}$ to 6.19 at $275 \mathrm{~K}$ and a slight increase from 6.16 at $361 \mathrm{~K}$ to 6.21 at $364 \mathrm{~K}$. When cooling back to $240 \mathrm{~K}$, a reverse change of $\varepsilon^{\prime}$ was observed. Such twostep dielectric anomalies with different variation amplitudes, ca. 2.1 and 0.05 in the vicinity of $T_{\mathrm{c} 1}$ and $T_{\mathrm{c} 2}$, respectively, strongly imply that the polar organic cations undergo different dynamic motion changes during the two-step phase transitions.

Further variable-temperature single-crystal XRD measurements revealed the structural change during phase transitions (Table S1). LTP crystallizes in the monoclinic $P 2_{1} / n$ space group with the asymmetric unit containing half $\left[\mathrm{Ni}(\mathrm{NCS})_{6}\right]^{4-}$ anion and two $\mathrm{Me}_{3} \mathrm{NCH}_{2} \mathrm{CH}_{2} \mathrm{OH}^{+}$cations. Each $\mathrm{Ni}^{2+}$ is coordinated to six $\mathrm{NCS}^{-}$to form a $\left[\mathrm{Ni}(\mathrm{NCS})_{6}\right]^{4-}$ inorganic unit, which is packed in a body-centred mode in the unit cell with $\mathrm{Me}_{3} \mathrm{NCH}_{2} \mathrm{CH}_{2} \mathrm{OH}^{+}$ cations occupying the vacancies (Fig. 2). Such packing mode is the same with a classical inorganic compound, $\mathrm{XeF}_{4}$, which also crystallizes in $P 2_{1} / n$ with a unit cell consisting of two $\mathrm{Xe}^{4+}$ adopting body-centred packing and eight $\mathrm{F}^{-}$adopting a nested distorted hexahedron arrangement, and thus 1 can be regarded as an anti- $\mathrm{XeF}_{4}$ molecular analogue containing additional 

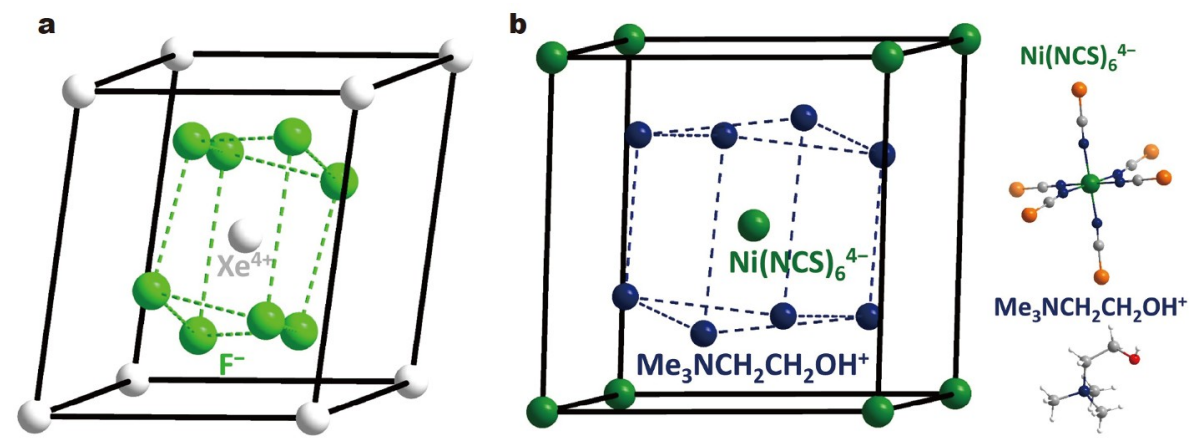

Scheme 1 Structure diagram of (a) $\mathrm{XeF}_{4}$ and (b) 1 .

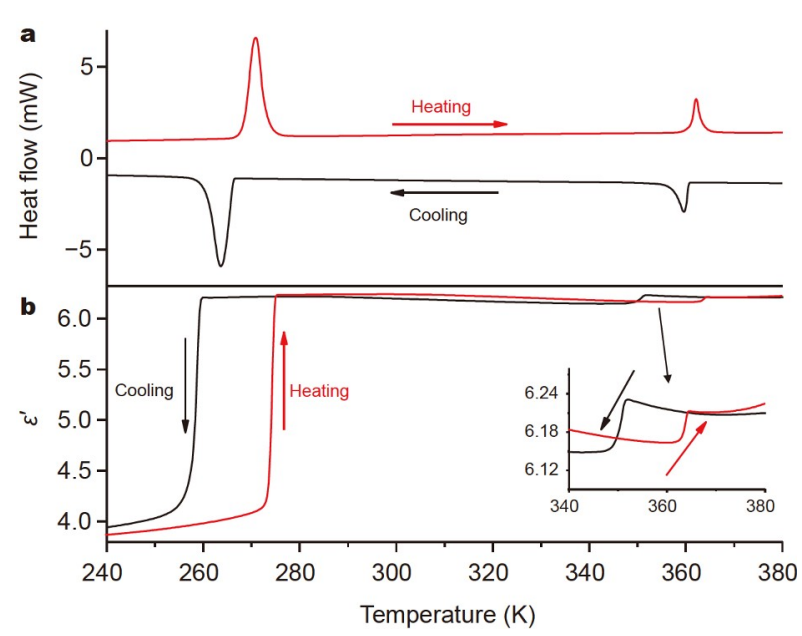

Figure 1 (a) DSC curves and (b) temperature-dependent real part of dielectric permittivity with a frequency of $100 \mathrm{kHz}$ for $\mathbf{1}$ during a cooling (black lines)-heating (red lines) cycle.

intermolecular $\mathrm{O}-\mathrm{H}$...S hydrogen bonds (O...S distances: $3.24-$ $3.28 \AA$, Table S2). Upon heating to RTP, 1 crystallizes in the high-symmetry $P 4 / m n c$ space group, with the asymmetric unit consisting of one eighth $\left[\mathrm{Ni}(\mathrm{NCS})_{6}\right]^{4-}$ and half $\mathrm{Me}_{3} \mathrm{NCH}_{2} \mathrm{CH}_{2^{-}}$ $\mathrm{OH}^{+}$. Accordingly, in RTP, the axial NCS${ }^{-}$ligands are four-fold disordered along the $c$ axis, the equatorial $\mathrm{NCS}^{-}$ligands are twofold disordered about the $a b$ plane, and each $\mathrm{Me}_{3} \mathrm{NCH}_{2} \mathrm{CH}_{2} \mathrm{OH}^{+}$ cation is two-fold disordered. Namely, the main differences between LTP and RTP come from the order-disorder transition of molecular components, and generate a conventional coolinginduced symmetry reduction from RTP to LTP.

Interestingly, upon further heating RTP to HTP, the crystal structure changes from tetragonal $P 4 / m n c$ to orthorhombic $\mathrm{Bbcm}$ (nonstandard setting of Cmce for convenience in structural comparison), with one eighth $\left[\mathrm{Ni}(\mathrm{NCS})_{6}\right]^{4-}$ anion and two four-fold disordered $\mathrm{Me}_{3} \mathrm{NCH}_{2} \mathrm{CH}_{2} \mathrm{OH}^{+}$cations in the asymmetric unit, showing an uncommon heating-induced symmetry reduction from RTP to HTP, i.e., an inverse symmetry breaking. As the organic cations are being dynamically disordered in both RTP and HTP, the symmetry reduction in HTP should mainly arise from the inorganic parts varying their dynamic motions and relative positions. In detail, the NCS ${ }^{-}$ligands being highly swaying around the $c$ axis in RTP turn to be ordered in HTP; meanwhile the eight $\mathrm{Ni} \cdots \mathrm{Ni}$ distances between adjacent inorganic units vary from an equivalent value (11.152 $\AA$ ) in RTP to unequal two groups (11.209 and 11.286 $\AA$ ) in HTP (Fig. S4). Such reduced dynamic motions of inorganic units could be ascribed to the slightly increased steric effect of the disordered organic cations from RTP to HTP, which is reflected by the increased effective volume of disordered organic cations from $165 \AA^{3}$ in RTP to $177 \AA^{3}$ in HTP (Fig. S5).
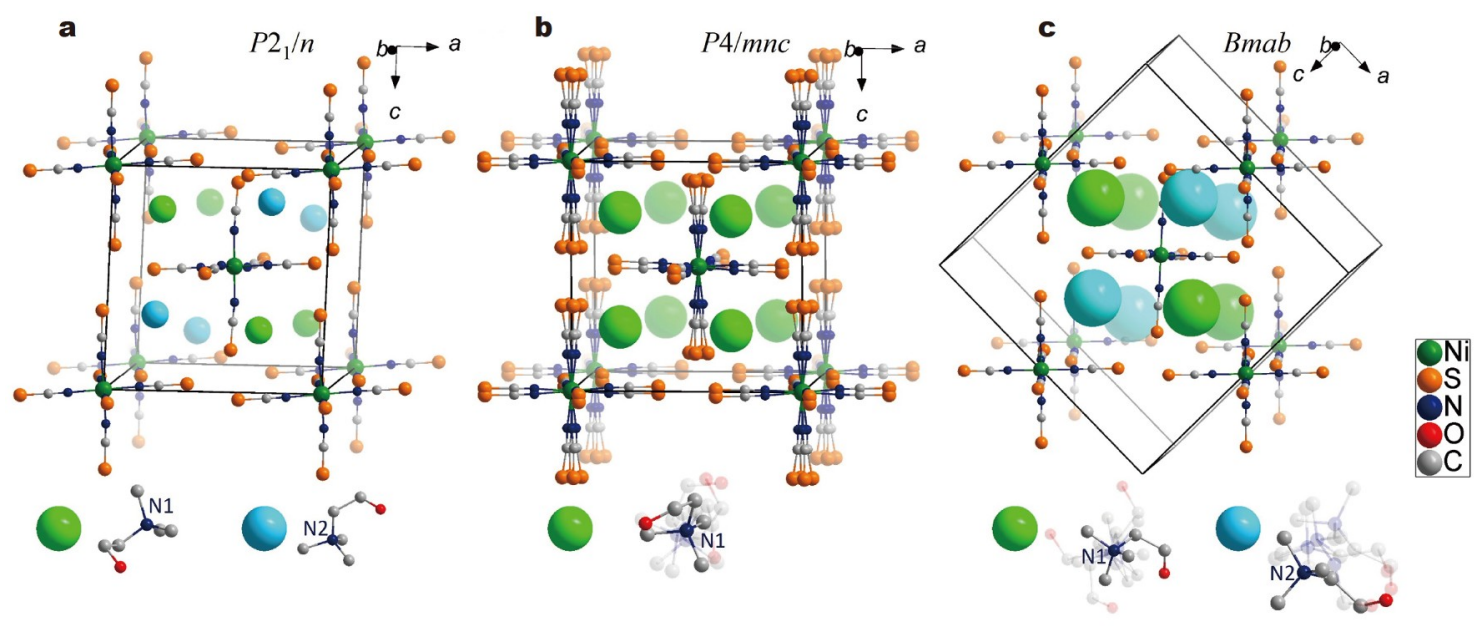

Figure 2 Crystal structures of (a) LTP, (b) RTP, and (c) HTP. The Ni, S, N, O, and C atoms are shaded in olive, orange, dark blue, red, and grey, respectively. For clarity, $\mathrm{H}$ atoms are omitted and the different $\mathrm{Me}_{3} \mathrm{NCH}_{2} \mathrm{CH}_{2} \mathrm{OH}^{+}$cations in the asymmetric unit are represented with green and sky-blue balls, respectively. 
The temperature dependence of the lattice parameters was monitored in the temperature range of 213-453 K via Pawley refinements on the variable-temperature PXRD patterns (Table S3), and the thermal expansion coefficients were calculated by the PASCal program (Tables S4 and S5) [30]. From LTP to HTP, the volume expansion coefficient increases from +150 $(7) \times 10^{-6} \mathrm{~K}^{-1}$ at $213-253 \mathrm{~K}(\mathrm{LTP})$ to $+197(10) \times 10^{-6} \mathrm{~K}^{-1}$ at $273-$ $353 \mathrm{~K}(\mathrm{RTP})$ then to $+210(6) \times 10^{-6} \mathrm{~K}^{-1}$ at $373-453 \mathrm{~K}(\mathrm{HTP})$, indicating an overall heating-enhanced molecular motion. When cooling from RTP to LTP at $T_{\mathrm{cl}}$, a large decrease of the $b$ axis by $4 \%$, a large increase of the $c$ axis by $3 \%$, and a large decrease of cell volume by ca. $2.1 \%$ were observed (Fig. 3). These facts well consist with the large enthalpy value and dielectric anomaly during phase transition in the vicinity of $T_{\mathrm{cl}}$, further supporting the underlying drastic change on molecular dynamics of molecular components between a frozen state and a highly-disordered state. In contrast, from RTP to HTP, the changes in the dynamical motions of molecular components are less drastic, and thus only a slight increase of cell volume by $0.08 \%$ and small variations of crystallographic axes by $0.1 \%-0.4 \%$ were observed during the phase transition at $T_{\mathrm{c} 2}$, which is reflected by the observed smaller enthalpy value and dielectric anomaly.

The number changes of symmetric elements during phase transitions from high-symmetric RTP ( $D_{4 \mathrm{~h}}$ point group) to lowsymmetric LTP ( $C_{2 \mathrm{~h}}$ point group) and HTP ( $D_{2 \mathrm{~h}}$ point group) are 4 and 2, respectively. According to Aizu rules, the phase transitions at $T_{\mathrm{c} 1}$ and $T_{\mathrm{c} 2}$ are classified into $4 / \mathrm{mmmF} 2 / \mathrm{m}$ and $4 /$ $m m m \mathrm{Fmmm}$ ferroelastic species, respectively, sharing the same paraelastic RTP phase. Based on the cell parameters at $T_{\mathrm{c} 1}$ and $T_{\mathrm{c} 2}$ deduced by linear fitting variable-temperature cell parameters (Supplementary information) [31], the total spontaneous strains for two ferroelastic phase transitions were estimated as 0.0603 for $T_{\mathrm{c} 1}$ and 0.0073 for $T_{\mathrm{c} 2}$.

The variable-temperature polarization microscopy was performed on single crystals perpendicular to their (101) planes to inspect possible ferroelastic transition (Figs S6 and S7). As shown in Fig. 4, no observable domain structures are present in paraelastic phase at $298 \mathrm{~K}$. After cooling to $250 \mathrm{~K}$, a multidomain pattern was observed, and the ferroelastic domains disappeared when heating back to $298 \mathrm{~K}$, well confirming a conventional ferroelastic transition at $T_{\mathrm{cl}}$. With further heating to $370 \mathrm{~K}$, the theoretically predicted two kinds of inter-ortho-
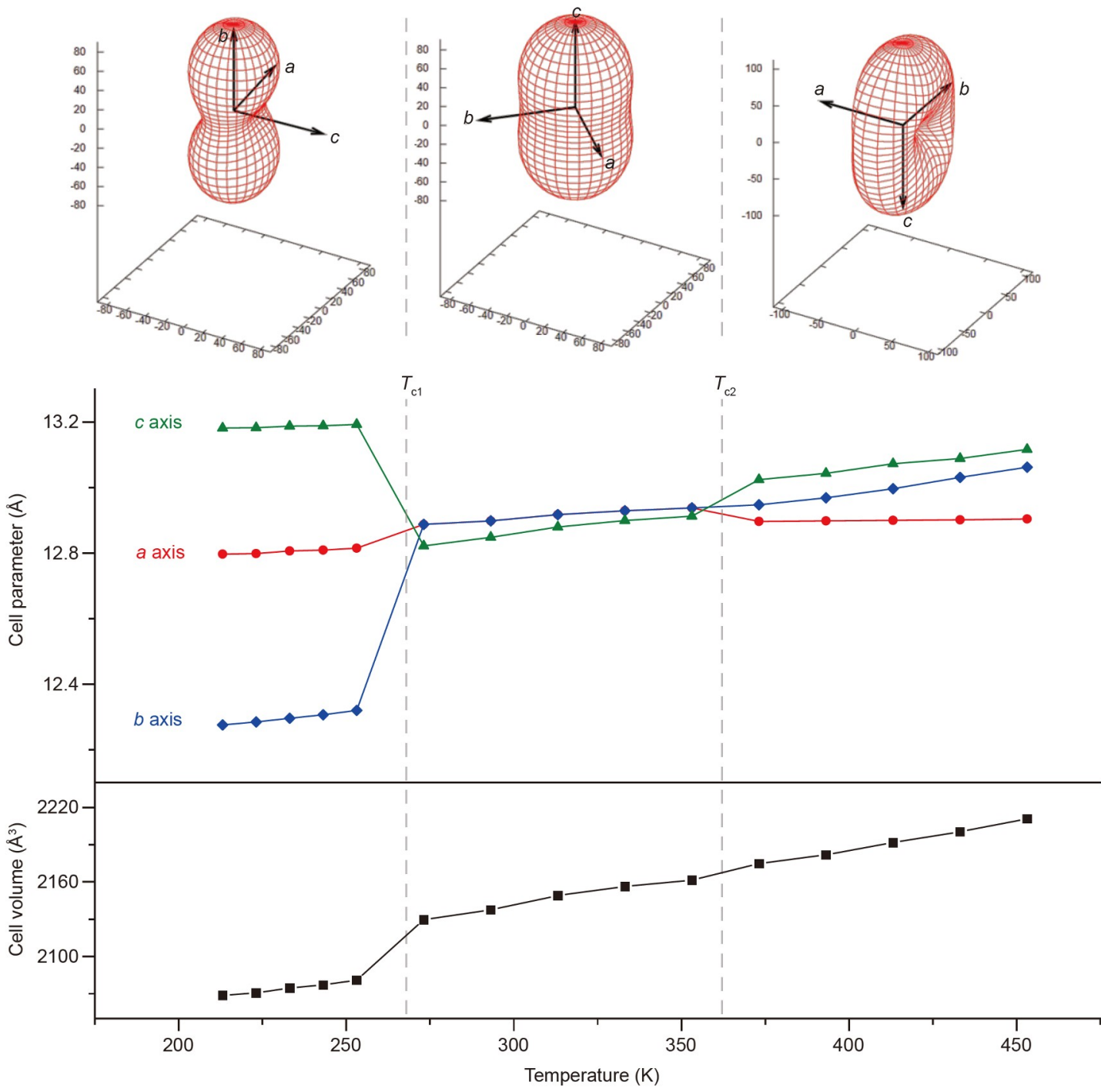

Figure 3 Temperature-dependent cell parameters and expansivity indicatrices along the $a, b$, and $c$ axes of $\mathbf{1}$. 

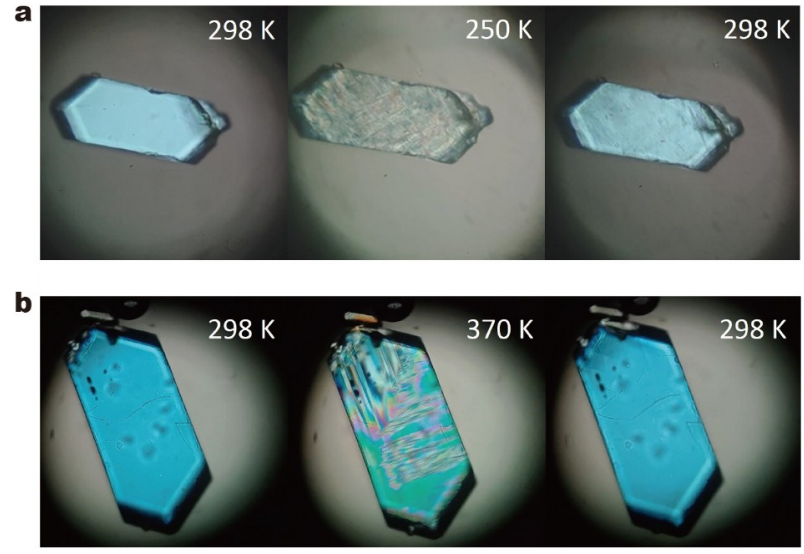

Figure 4 Evolution of multi-domain structures of the ferroelastic phase and single-domain paraelastic phase in the cooling-heating runs.

gonal domains could be clearly distinguished, and then completely disappeared after cooling back to $298 \mathrm{~K}$. Such unusual observation well confirms an inverse symmetry-breaking ferroelasticity at $T_{\mathrm{c} 2}$ that renders 1 a high-temperature ferroic materials. It is worth noting that, different from the other rarely documented molecular hybrid compounds revealing inverse symmetry-breaking ferroelastic phase transitions, 1 exhibits an additional conventional symmetry-breaking ferroelastic phase transition at lower temperature region; thus, 1 presents a very scarce instance being paraelastic phase at room temperature while possessing high- and low- temperature dual ferroelasticity.

This unprecedented character of $\mathbf{1}$ is highly associated with the high-symmetry structure hosting crystallographically disordered $\mathrm{NCS}^{-}$ligands at room temperature. To date, nine anti$\mathrm{XeF}_{4}$ molecular analogues with a general formula of $\mathrm{A}_{4}\left[\mathrm{M}(\mathrm{NCS})_{6}\right]$ have been documented (Table S6), but all of them, except $\left(\mathrm{Me}_{2} \mathrm{EtNH}\right)_{4}\left[\mathrm{Ni}(\mathrm{NCS})_{6}\right]$, do not have crystallographically disordered $\mathrm{NCS}^{-}$ligands in the available temperature range, hence possessing crystal symmetry not higher than orthorhombic symmetry. A detailed comparison on the phase transitions of these documented instances suggests that the size match between inorganic and organic components plays a very important role in hosting crystallographically dynamic disorder for $\mathrm{NCS}^{-}$ligands. For instance, the relatively larger cations (such as $\mathrm{Et}_{3} \mathrm{NH}^{+}$and $\mathrm{Ph}_{3} \mathrm{MeP}^{+}$) hardly form crystallographic disorder owing to a too-large steric effect, while the smaller ones (such as $\mathrm{Me}_{3} \mathrm{NH}^{+}, \mathrm{Me}_{4} \mathrm{~N}^{+}$and $\mathrm{Me}_{4} \mathrm{P}^{+}$) can hardly prop up the bodycentred packed inorganic parts to give a tetragonal phase. In this sense, the size-matchable $\mathrm{Me}_{3} \mathrm{NCH}_{2} \mathrm{CH}_{2} \mathrm{OH}^{+}$and $\mathrm{Me}_{2} \mathrm{EtNH}^{+}$in 1 and $\left(\mathrm{Me}_{2} \mathrm{EtNH}\right)_{4}\left[\mathrm{Ni}(\mathrm{NCS})_{6}\right]$, respectively, play essential roles in inducing $\mathrm{NCS}^{-}$swaying, through intermolecular $\mathrm{O} / \mathrm{N}-\mathrm{H} \cdots \mathrm{S}$ hydrogen bonds, and finally leading to a highly synergetic motion for cations and anions to yield a tetragonal phase [32]. Moreover, different from $\left(\mathrm{Me}_{2} \mathrm{EtNH}\right)_{4}\left[\mathrm{Ni}(\mathrm{NCS})_{6}\right]$ undergoing conventional phase transitions with a step-wise heating-induced symmetry increase $\left(P 2_{1} / n-P b n m-A c a m-P 4 / m n c\right), 1$ undergoes unusual phase transitions with a heating-induced symmetry increase and then a heating-induced symmetry reduction $\left(P 2_{1} / n-P 4 / m n c-B m a b\right)$, benefiting from a delicate interplay between matchable inorganic units and organic cations.

In conclusion, we present a new anti- $\mathrm{XeF}_{4}$ molecular analogue, i.e., 1, which shows unprecedented high- and low-temperature dual ferroelasticity through $4 / \mathrm{mmmF} 2 / \mathrm{m}$ and $4 /$ $m m m$ Fmmm ferroelastic phase transitions at 269 and $360 \mathrm{~K}$ with spontaneous strain of 0.0603 and 0.0073 , respectively. Detailed structural study revealed that the highly synergetic rotation of $\mathrm{Me}_{3} \mathrm{NCH}_{2} \mathrm{CH}_{2} \mathrm{OH}^{+}$and $\mathrm{NCS}^{-}$through intermolecular hydrogen bonds makes 1 possessing a high-symmetry tetragonal phase at room temperature, and the complicate and delicate order-disorder transitions of matchable organic cations and inorganic anions play essential roles in inducing symmetry-reduced phases at both low- and high-temperature regions. This work not only presents a very scarce instance with dual ferroelasticity, but also enhances our understanding on nontrivial inverse symmetrybreaking phase transitions, and inspires future exploration of high-temperature ferroic materials in molecular hybrid crystals.

\section{Received 25 August 2021; accepted 9 September 2021;} published online 15 October 2021

1 Fesenko EG, Gavrilyatchenko VG, Semenchev AF. Domain structure of multiaxial ferroelectric crystals. Ferroelectrics, 1989, 100: 195-207

2 Wadhawan VK. Ferroelasticity. Bull Mater Sci, 1984, 6: 733-753

3 Sapriel J. Domain-wall orientations in ferroelastics. Phys Rev B, 1975, 12: $5128-5140$

4 Salje EKH. Ferroelastic materials. Annu Rev Mater Res, 2012, 42: 265283

5 Aizu K, Kumada A, Yumoto $\mathrm{H}$, et al. Simultaneous ferroelectricity and ferroelasticity of $\mathrm{Gd}_{2}\left(\mathrm{MoO}_{4}\right)_{3}$. J Phys Soc Jpn, 1969, 27: 511

6 Brixner LH, Bierstedt PE, Jaep WF, et al. $\alpha-\mathrm{Pb}_{3}\left(\mathrm{PO}_{4}\right)_{2}-\mathrm{A}$ pure ferroelastic. Mater Res Bull, 1973, 8: 497-503

7 Fillingham PJ. Domain structure and twinning in crystals of vanadium dioxide. J Appl Phys, 1967, 38: 4823-4829

8 Hill C, Weber MC, Lehmann J, et al. Role of the ferroelastic strain in the optical absorption of $\mathrm{BiVO}_{4}$. APL Mater, 2020, 8: 081108

9 An Z, Xie S, Zhang N, et al. Ferroelastic domain hierarchy in the intermediate state of $\mathrm{PbZr}_{0.98} \mathrm{Ti}_{0.02} \mathrm{O}_{3}$ single crystal. APL Mater, 2021, 9: 030702

$10 \mathrm{Xu}$ WJ, Du ZY, Zhang WX, et al. Structural phase transitions in perovskite compounds based on diatomic or multiatomic bridges. CrystEngComm, 2016, 18: 7915-7928

11 Wang SS, Chen XX, Huang B, et al. Unique freezing dynamics of flexible guest cations in the first molecular postperovskite ferroelectric: $\left(\mathrm{C}_{5} \mathrm{H}_{13} \mathrm{NBr}\right)\left[\mathrm{Mn}\left(\mathrm{N}(\mathrm{CN})_{2}\right)_{3}\right]$. CCS Chem, 2019, 1: 448-454

$12 \mathrm{Xu} \mathrm{WJ}$, Zeng $\mathrm{Y}$, Yuan $\mathrm{W}$, et al. A large room-temperature entropy change in a new hybrid ferroelastic with an unconventional bondswitching mechanism. Chem Commun, 2020, 56: 10054-10057

13 Liu DX, Xie KP, Zhang WX, et al. Structural insights into a new family of three-dimensional thiocyanate-bridged molecular double perovskites. CrystEngComm, 2021, 23: 2208-2214

14 Zhang SY, Shu X, Zeng Y, et al. Molecule-based nonlinear optical switch with highly tunable on-off temperature using a dual solid solution approach. Nat Commun, 2020, 11: 2752

15 Chen Y, Zhu T, Xiong Z, et al. An organic-inorganic hybrid birefringent material with diverse functional groups. Chem Commun, 2021, 57: 6668-6671

16 Kou B, Zhang W, Ji C, et al. Tunable optical absorption in lead-free perovskite-like hybrids by iodide management. Chem Commun, 2019, 55: $14174-14177$

17 Aizu K. Determination of the state parameters and formulation of spontaneous strain for ferroelastics. J Phys Soc Jpn, 1970, 28: 706-716

18 He L, Zhou L, Shi PP, et al. One-dimensional cadmium thiocyanate perovskite ferroelastics tuned by halogen substitution. Chem Mater, 2019, 31: 10236-10242

19 Cao YJ, Zhou L, Shi PP, et al. H/F substituted perovskite compounds with above-room-temperature ferroelasticity: $\left[\left(\mathrm{CH}_{3}\right)_{4} \mathrm{P}\right]\left[\mathrm{Cd}(\mathrm{SCN})_{3}\right]$ and $\left[\left(\mathrm{CH}_{3}\right)_{3} \mathrm{PCH}_{2} \mathrm{~F}\right]\left[\mathrm{Cd}(\mathrm{SCN})_{3}\right]$. Chem Commun, 2019, 55: 8418-8421

$20 \mathrm{Hu} \mathrm{WH}, \mathrm{Xu} \mathrm{WJ}$, Meng QR, et al. Switching hydrogen bonds to readily interconvert two room-temperature long-term stable crystalline polymorphs in chiral molecular perovskites. Chem Commun, 2019, 55: 


\section{$11555-11558$}

21 Xu WJ, Li PF, Tang YY, et al. A molecular perovskite with switchable coordination bonds for high-temperature multiaxial ferroelectrics. J Am Chem Soc, 2017, 139: 6369-6375

22 Ye $\mathrm{H}, \mathrm{Hu} \mathrm{WH}, \mathrm{Xu} \mathrm{WJ}$, et al. Two enantiomeric perovskite ferroelectrics with a high $T_{\mathrm{c}}$ raised by inserting intermolecular hydrogen bonds. APL Mater, 2021, 9: 031102

$23 \mathrm{Xu}$ WJ, Romanyuk K, Zeng Y, et al. Statics and dynamics of ferroelectric domains in molecular multiaxial ferroelectric $\left(\mathrm{Me}_{3} \mathrm{NOH}\right)_{2}$ [KCo $\left.(\mathrm{CN})_{6}\right]$. J Mater Chem C, 2021, 9: 10741-10748

24 Liu HY, Zhang HY, Chen XG, et al. Molecular design principles for ferroelectrics: Ferroelectrochemistry. J Am Chem Soc, 2020, 142: 15205-15218

25 Jona F, Shirane G. Ferroelectric Crystals. Oxford: Pergamon, 1962, 108

26 Zhang J, Yao WW, Sang L, et al. Multi-step structural phase transitions with novel symmetry breaking and inverse symmetry breaking characteristics in a $\left[\mathrm{Ag}_{4} \mathrm{I}_{6}\right]^{2-}$ cluster hybrid crystal. Chem Commun, 2020, 56: $462-465$

27 Szafrański M. Reverse group-subgroup relation at the ferroelastic phase transition in $\left[\left(\mathrm{C}_{2} \mathrm{H}_{5}\right)_{4} \mathrm{~N}\right]\left[\left(\mathrm{CH}_{3}\right)_{4} \mathrm{~N}\right] \mathrm{MnBr}_{4}$. Cryst Growth Des, 2016, 16: 3771-3776

28 Miao LP, Chu LL, Han XB, et al. A ferroelastic molecular rotor crystal showing inverse temperature symmetry breaking. Inorg Chem Front, 2021, 8: 2809-2816

29 Yuan W, Zeng Y, Tan YY, et al. A new ferroelastic hybrid material with a large spontaneous strain: $\left(\mathrm{Me}_{3} \mathrm{NOH}\right)_{2}\left[\mathrm{ZnCl}_{4}\right]$. Chem Commun, 2019, 55: 8983-8986

30 Cliffe MJ, Goodwin AL. PASCal: A principal axis strain calculator for thermal expansion and compressibility determination. J Appl Crystlogr, 2012, 45: 1321-1329

31 Carpenter MA, Salje EKH, Graeme-Barber A. Spontaneous strain as a determinant of thermodynamic properties for phase transitions in minerals. Eur J Mineral, 1998, 10: 621-691

32 Jia ZH, Liu JY, Liu DX, et al. Four-step thermosensitive dielectric response arising from motionable low-symmetry ammonium confined in deformable supramolecular cages. J Mater Chem C, 2021, 9: 8076-8082

Acknowledgements This work was supported by the National Natural Science Foundation of China (22071273 and 21821003), and the Local Innovative and Research Teams Project of Guangdong Pearl River Talents Program (2017BT01C161).

Author contributions Zhang WX, Chen XM and Liu DX conceived the idea, designed the experiments and co-wrote the manuscript; Liu DX engineered the samples; Liu DX, Chen XX and Ye ZM performed the experiments; all authors contributed to the general discussion.

Conflict of interest The authors declare that they have no conflict of interest.
Supplementary information Experimental details and supporting data are available in the online version of the paper.

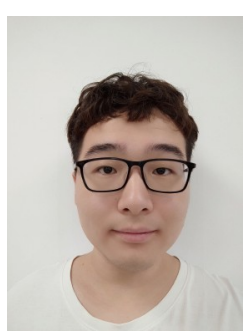

De-Xuan Liu was born in 1996 and obtained his BSc degree in 2018 at Sun Yat-Sen University (SYSU). He is a $\mathrm{PhD}$ candidate in inorganic chemistry at SYSU. His research is focused on functional hybrid compounds.

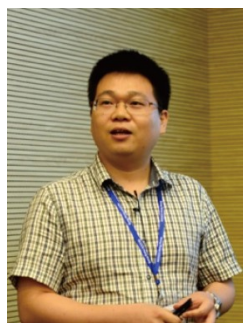

Wei-Xiong Zhang obtained his BSc degree in 2004 and $\mathrm{PhD}$ degree in 2009 at SYSU, and was a JSPS (Japan Society for the Promotion of Science) postdoc at Tohoku University from 2010 to 2012 . He joined SYSU in 2012, and became a professor in 2018. His current research interest is in crystal engineering of multi-component dense crystals, especially the structural-phase-transition functional crystals and energetic crystals.

\title{
一例具有高低温双铁弹性的新型杂化晶体: $\left(\mathrm{Me}_{3} \mathrm{NCH}_{2} \mathrm{CH}_{2} \mathrm{OH}\right)_{4}\left[\mathrm{Ni}(\mathrm{NCS})_{6}\right]$
}

\author{
刘德轩, 陈晓娴, 叶子铭, 张伟雄", 陈小明
}

摘要 本文报道了一例具有反 $\mathrm{XeF}_{4}$ 结构的新型杂化晶体 $\left(\mathrm{Me}_{3} \mathrm{NCH}_{2}-\right.$ $\left.\mathrm{CH}_{2} \mathrm{OH}\right)_{4}\left[\mathrm{Ni}(\mathrm{NCS})_{6}\right]$, 其分子组分的较复杂有序-无序转变使得该化合 物在 269 和 $360 \mathrm{~K}$ 发生两步可逆相变. 这两步相变伴随着 $P 2_{1} / n-P 4 / m n c-$ $B m a b$ 的空间群变化, 即分别属于正常的降温对称性破缺和反常的升温 对称性破缺现象, 因此使得该化合物可在低温和高温均展现出铁弹性 (自发极化强度分别为 0.0603 和 0.0073 ). 这种不同寻常的高低温双铁弹 性的发现和研究, 有助于加深对反常对称性破缺相变的理解, 并为今后 在分子杂化晶体中探索高温铁性材料提供重要线索. 